\title{
Lower bound multiscale element for in situ cast joints in triaxial stress
}

\author{
Herfelt, Morten Andersen; Poulsen, Peter Noe; Hoang, Linh Cao; Jensen, Jesper Frøbert
}

\section{Published in:}

Engineering Structures

Link to article, DOI:

10.1016/j.engstruct.2017.12.054

Publication date:

2018

Document Version

Peer reviewed version

Link back to DTU Orbit

Citation $(A P A)$ :

Herfelt, M. A., Poulsen, P. N., Hoang, L. C., \& Jensen, J. F. (2018). Lower bound multiscale element for in situ cast joints in triaxial stress. Engineering Structures, 167, 340-350.

https://doi.org/10.1016/j.engstruct.2017.12.054

\section{General rights}

Copyright and moral rights for the publications made accessible in the public portal are retained by the authors and/or other copyright owners and it is a condition of accessing publications that users recognise and abide by the legal requirements associated with these rights.

- Users may download and print one copy of any publication from the public portal for the purpose of private study or research.

- You may not further distribute the material or use it for any profit-making activity or commercial gain

- You may freely distribute the URL identifying the publication in the public portal 


\title{
Lower bound multiscale element for in-situ cast joints in triaxial stress
}

\author{
Morten A. Herfelt ${ }^{\mathrm{a}, \mathrm{b}}$, Peter N. Poulsen ${ }^{\mathrm{b}}$, Linh C. Hoang ${ }^{\mathrm{b}}$, Jesper F. Jensen ${ }^{\mathrm{a}}$ \\ ${ }^{a}$ NIRAS A/S, Sortemosevej 17, 3450 Allerød, Denmark \\ ${ }^{b}$ Department of Civil Engineering, Technical University of Denmark, Brovej, Building \\ 118, 2800 Kgs. Lyngby, Denmark
}

\begin{abstract}
In practice, precast concrete structures are often being designed by manual methods and linear finite element analysis in the ultimate limit state. This practice leads to suboptimal structures, and the behaviour of the in-situ cast joints are unaccounted for. More accurate and efficient means of design are therefore needed, and a framework based on finite element limit analysis is being developed. In this paper, a one-dimensional multiscale joint element is presented, and a mechanical model is proposed as the yield function of the macro element. The scope of the model is to capture the behaviour of joints in three dimensions subjected to triaxial stress, and the resulting mathematical optimisation problem fits the format of semidefinite programming. The presented joint element is analysed and a real size example of a four-storey stairwell subjected to shear and torsion of precast concrete is presented. The influence of the joints on the behaviour of the stairwell is assessed.
\end{abstract}

Keywords: In-situ cast joints, Precast concrete, Finite element limit analysis, Semidefinite programming, Yield function, Multiscale

\section{Introduction}

Precast concrete elements are widely used in the construction industry as they provide a number of benefits, however, joints cast on the construction site to connect the precast elements pose several challenges. The current practice is to design the joints as the weakest part of the structure. This

Email address: mahe@niras.dk (Morten A. Herfelt) 
makes analysis and design by general purpose finite element software inaccurate as the behaviour of the joints is unaccounted for.

Several types of joints are used in precast concrete structures, e.g. slabto-beam joints, beam-to-column joints, and panel-to-panel joints, see Fig. 1. The panel-to-panel joints, also called shear joints, are of particular interest as the lateral stability usually is ensured by shear walls composing of precast wall panels. During the 1970 s and 80s several papers were published on the topic of shear joints including several experimental studies $[1,2,3]$, however, to the best knowledge of the authors, no experimental studies on the behaviour of joints in three-dimensions have been published. The Eurocode 2 [4] uses a simple, empirical design equation, which only considers the interface and not the actual stress state within the joint. Both types of joints shown in Fig. 1 transfer shear from one structural plane to another, and must therefore experience a triaxial stress field which is not accounted for by current design methods.

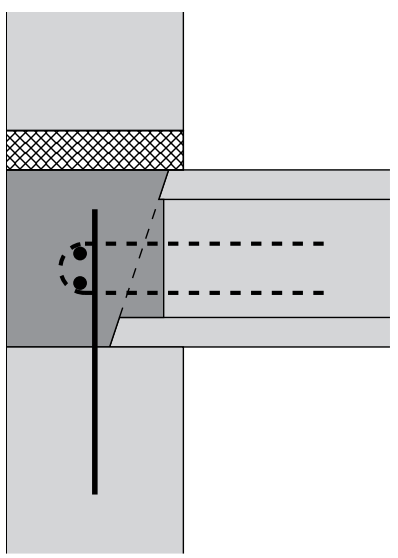

(a)

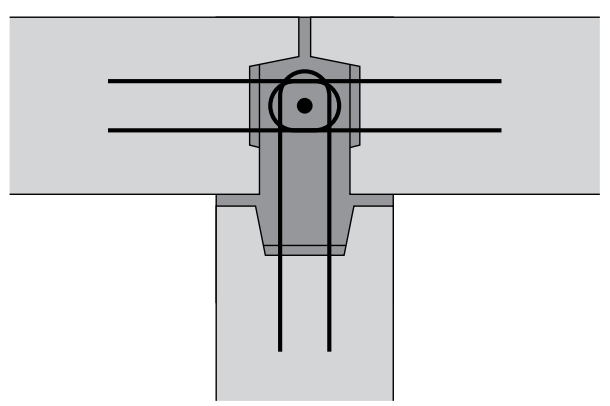

(b)

Figure 1: a) Vertical section of slab-to-panel joint reinforced with U-bar loops and embedded rebars. b) Horizontal section of panel-to-panel T-joint reinforced with U-bar loops extruding from all three panels.

The experiments by Hansen and Olesen [3] featured several specimens, where the U-bar loops were placed with a considerable distance. These experiments displayed a lower capacity and the core of the joint was completely destroyed upon failure. A detailed model based on finite element limit analysis captured this behaviour to a satisfactory degree [5]. The joint model presented in this paper will attempt to account for this behaviour in three 
dimensions, as the reinforcement layout necessarily will affect the capacity of joints in triaxial stress as well.

Manual limit analysis is widely used in practice as a tool for assessment of the ultimate limit state behaviour of precast concrete structures. The framework is based on the extremum principles [see e.g. 6, 7, 8], and several methods have been developed within this framework, e.g. the yield line theory [9]. Models for shear joints based on limit analysis have likewise been developed; these models include both upper bound models [10, 11, 12] and lower bound models $[11,13]$, however, these models are only concerned with the two-dimensional case, i.e. joints between precast elements in the same plane.

Finite element limit analysis is based on the same extremum principles as the manual limit analysis and the element discretisation of the finite element method, and it can be considered as a special case of the general finite element method. The method was developed in the late 1960s and 70s [14, 15] and since then several researchers have contributed to the further development of the field [16, 17, 18, 19, 20]. Herfelt et al. [5] presented a detailed model for two-dimensional shear joints and the findings were used to develop a onedimensional multiscale joint element with a mechanical submodel as the yield criterion capable of modelling two-dimensional shear joints [21].

In this paper a one-dimensional multiscale joint element for three-dimensional analysis is presented analogous to the joint element developed for twodimensional shear joints [21]. The joint element is compatible with the generalised plane stress element [22] and uses a simplified mechanical model as the yield criterion. The general concept is visualised for the two-dimensional case in Fig. 2 where three scales are shown, namely the structural level, the element level, and the submodel level.

Due to the triaxial stress state, the yield function submodel will be formulated for semidefinite programming and second-order constraints. A brief introduction to semidefinite programming as well as second-order cone programming will be given in Sec. 2, where the conic representation of the Mohr-Coulomb criterion will be given as well. The behaviour of the multiscale element will be analysed and compared to the equation in the Eurocode 2. Finally, a real size structure is analysed using the proposed joint element and the generalised plane stress element [22], and the influence of the joint elements is discussed. 


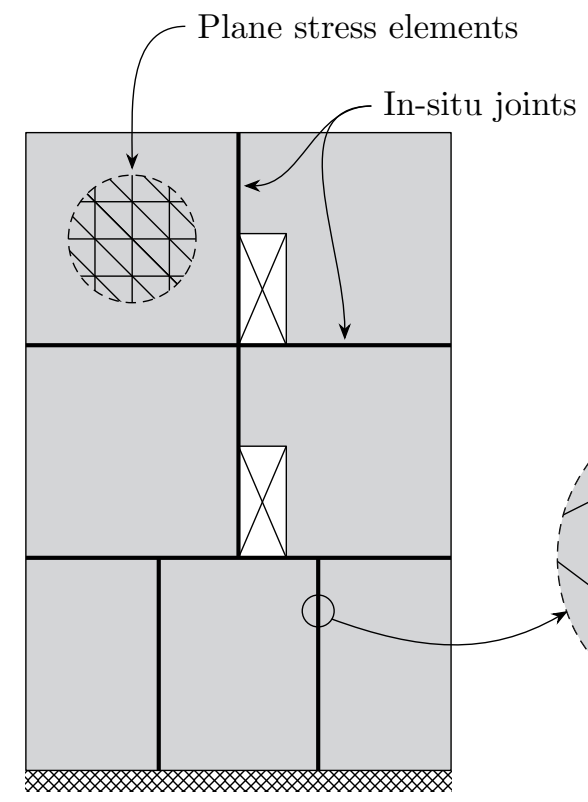

(a)
Corbel mechanism

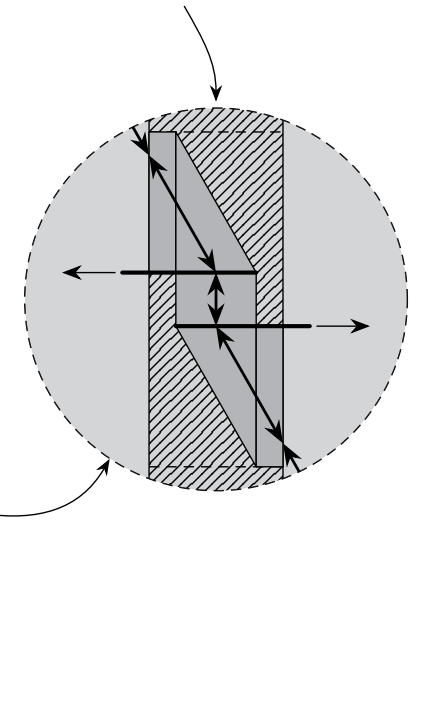

(c)

Figure 2: The general concept of the multiscale joint element shown in two dimensions: a) Precast concrete structure on the structural level, b) Joint element and plane stress elements on the element level, c) corbel mechanisms and load path on the submodel level.

\section{Convex optimisation}

Convex optimisation is used in many fields of engineering and an extensive research effort has gone into developing efficient algorithms for solving these classes of problems $[23,24,25]$. Second-order cone programming (SOCP) and semidefinite programming (SDP) are subclasses of convex optimisation that have been used in the field of finite element limit analysis for more than a decade $[26,27]$.

First and foremost, we introduce the $k$-dimensional second-order cone defined as the set

$$
\mathcal{Q}_{k}=\left\{\boldsymbol{x} \mid \boldsymbol{x} \in \mathbb{R}^{k}, x_{1} \geq \sqrt{x_{2}^{2}+\cdots+x_{k}^{2}}\right\}
$$

The standard form of a second-order cone program is commonly stated as

$$
\begin{array}{ll}
\text { maximise } & \boldsymbol{c}^{T} \boldsymbol{x} \\
\text { subject to } & \mathbf{A} \boldsymbol{x}=\boldsymbol{b} \\
& \boldsymbol{x}_{i} \in \mathcal{Q}_{k_{i}}, \quad i=1,2, \ldots, q
\end{array}
$$


where the $\boldsymbol{x}$ is the optimisation variables and $q$ is the number of secondorder cones. SOCP is a generalisation of linear programming (LP), and (2) is reminiscent of the well-known standard form of LP.

Semidefinite programing uses so-called matrix variables, symmetric matrices which are required to be positive-semidefinite, i.e. a $n \times n$ matrix $\mathbf{F}$ satisfies

$$
\boldsymbol{x}^{T} \mathbf{F} \boldsymbol{x} \geq 0 \text { for all } \boldsymbol{x} \in \mathbb{R}^{n}
$$

A curved inequality sign $\succeq$ is often used to denote that a matrix is positive semidefinite, e.g. $\mathbf{F} \succeq 0$. Vandenberghe and Boyd [28] uses the following, very compact form of the semidefinite program:

$$
\begin{array}{ll}
\text { maximise } & \boldsymbol{c}^{T} \boldsymbol{x} \\
\text { subject to } & \mathbf{F}(\boldsymbol{x}) \succeq 0
\end{array}
$$

with

$$
\mathbf{F}(\boldsymbol{x})=\mathbf{F}_{0}+\sum_{i=1}^{m} \mathbf{F}_{i} x_{i}
$$

where $\mathbf{F}_{i}$ are symmetric matrices. $\mathbf{F}(\boldsymbol{x}) \succeq 0$ is a so-called linear matrix inequality (LMI), which makes it possible to impose constraints on the eigenvalues of symmetric matrices, e.g. the stress tensor.

\subsection{Conic representation of the Mohr-Coulomb criterion}

The Mohr-Coulomb criterion is commonly used for concrete and soils. In principal stresses the criterion including tension cut-off is given as

$$
\begin{aligned}
\sigma_{1} & \leq f_{t} \\
k \sigma_{1}-\sigma_{3} & \leq f_{c}
\end{aligned}
$$

where $\sigma_{1} \geq \sigma_{2} \geq \sigma_{3}$ are the principal stresses, $f_{t}$ is the uniaxial tensile strength, and $f_{c}$ is the uniaxial compressive strength. $k$ is a friction parameter defined as

$$
k=\left(\sqrt{\mu^{2}+1}+\mu\right)^{2}
$$

with $\mu=\tan \theta$, where $\theta$ is the internal angle of friction. $k=4$ corresponding to $\mu=0.75$ and $\theta \approx 37^{\circ}$ is commonly used for normal strength concrete.

The principal stresses are the eigenvalues of the concrete stress tensor $\boldsymbol{\sigma}_{c}$, thus, (4) can be represented using linear matrix inequalities [26, 29, 30]. 
Utilising that $\mathbf{F} \succeq 0$ means that the smallest eigenvalue of $\mathbf{F}$ must be nonnegative, and that $-\mathbf{F} \succeq 0$ means that the largest eigenvalue of $\mathbf{F}$ must be non-positive, the separation criterion (4a) can be rewritten as

$$
-\boldsymbol{\sigma}_{c}+f_{t} \mathbf{I} \succeq 0
$$

where $\mathbf{I}$ is the identity matrix. The sliding criterion (4b) uses two principal stresses and it is therefore necessary to introduce an auxiliary variable $\alpha_{1}$, to obtain

$$
\begin{array}{r}
-\sigma_{1}+\alpha_{1} \geq 0 \\
\sigma_{3}-k \alpha_{1}+f_{c} \geq 0
\end{array}
$$

and

$$
\begin{aligned}
-\boldsymbol{\sigma}_{c}+\alpha_{1} \mathbf{I} & \succeq 0 \\
\boldsymbol{\sigma}_{c}+\left(f_{c}-k \alpha_{1}\right) \mathbf{I} & \succeq 0
\end{aligned}
$$

using the stress tensor $\boldsymbol{\sigma}_{c}$. The three LMIs of (6) and (7) can be reduced to two, and the Mohr-Coulomb criterion with a tension cut-off (4) can be stated as

$$
\begin{aligned}
- & \boldsymbol{\sigma}_{c}+\alpha_{2} \mathbf{I} \succeq 0 \\
& \boldsymbol{\sigma}_{c}+\left(f_{c}-k \alpha_{1}\right) \mathbf{I} \succeq 0 \\
& \alpha_{2}-\alpha_{1} \geq 0 \\
& \alpha_{2}-f_{t} \geq 0
\end{aligned}
$$

For plane stress problems (8) can be used, however, it is more efficient in this case to use the second-order cone representation instead. In plane stress, the criterion including tension cut-off is given as

$$
\begin{aligned}
\sigma_{1} & \leq f_{t} \\
k \sigma_{1}-\sigma_{2} & \leq f_{c} \\
-\sigma_{2} & \leq f_{c}
\end{aligned}
$$

where $\sigma_{1} \geq \sigma_{2}$ are the two principal stresses given as

$$
\left.\begin{array}{l}
\sigma_{1} \\
\sigma_{2}
\end{array}\right\}=\frac{\sigma_{x}+\sigma_{y}}{2} \pm \sqrt{\left(\frac{\sigma_{x}-\sigma_{y}}{2}\right)^{2}+\tau_{x y}^{2}}
$$


Introducing the auxiliary variables

$$
p_{m}=-\frac{\sigma_{x}+\sigma_{y}}{2}, \quad \sigma_{d}=\frac{\sigma_{x}-\sigma_{y}}{2}
$$

and the second-order constraint

$$
\varphi \geq \sqrt{\sigma_{d}^{2}+\tau_{x y}^{2}}
$$

the Mohr-Coulomb criterion for plane stress can be rewritten as

$$
\begin{aligned}
-p_{m}+\varphi & \leq f_{t} \\
(1-k) p_{m}+(k+1) \varphi & \leq f_{c} \\
p_{m}+\varphi & \leq f_{c}
\end{aligned}
$$

and the criterion for plane stress requires a total of five linear constraints and one second-order constraint.

\section{Finite element limit analysis}

The presented joint element is to be implemented in a framework based on finite element limit analysis for design of precast concrete structures. The mathematical optimisation problem of lower bound limit analysis can be stated as:

$$
\begin{array}{ll}
\text { maximise } & \lambda \\
\text { subject to } & \hat{\mathbf{B}}^{T} \hat{\boldsymbol{\sigma}}=\hat{\boldsymbol{p}} \lambda+\hat{\boldsymbol{p}}_{0} \\
& f\left(\hat{\boldsymbol{\sigma}}_{i}\right) \leq 0, \quad i=1,2, \ldots, m
\end{array}
$$

where $\hat{\boldsymbol{\sigma}}$ represents the global discretised stress field, $\hat{\mathbf{B}}^{T}$ is commonly denoted the equilibrium matrix, and $f$ is the yield function. The optimisation problem (11) represents the global problem, e.g. the entire structure, and the scope of the problem is to find a statically admissible stress field that maximises the load carrying capacity of the structure for a given load action described by a constant part $\hat{\boldsymbol{p}}_{0}$ and a scalable part $\hat{\boldsymbol{p}} \lambda$, where the load factor $\lambda$ is sought to be maximised. A stress field that satisfies equilibrium is ensured by the linear equations $\hat{\mathbf{B}}^{T} \hat{\boldsymbol{\sigma}}=\hat{\boldsymbol{p}} \lambda+\hat{\boldsymbol{p}}_{0}$, and a stress field that does not violate the yield criterion in any points is ensured by the inequalities $f\left(\hat{\boldsymbol{\sigma}}_{i}\right) \leq 0$.

For the joint element presented in Sec. 4, the yield function $f$ will represent a submodel, i.e. an advanced yield function comprising a mechanical 
model and sub-element level stress fields. By expanding the yield function $f$, the lower bound problem (11) can be stated as:

$$
\begin{array}{lll}
\text { maximise } & \lambda \\
\text { subject to } & \hat{\mathbf{B}}^{T} \hat{\boldsymbol{\sigma}}=\hat{\boldsymbol{p}} \lambda+\hat{\boldsymbol{p}}_{0} & \\
& \hat{\mathbf{C}}_{\sigma} \hat{\boldsymbol{\sigma}}+\hat{\mathbf{C}}_{\alpha} \hat{\boldsymbol{\alpha}}+\hat{\mathbf{C}}_{\gamma} \hat{\gamma}=\hat{\boldsymbol{C}}_{0} & \\
& \hat{\mathbf{E}}_{\sigma} \hat{\boldsymbol{\sigma}}+\hat{\mathbf{E}}_{\alpha} \hat{\boldsymbol{\alpha}}+\hat{\mathbf{E}}_{\gamma} \hat{\gamma} \leq \hat{\boldsymbol{E}}_{0} & \\
& \hat{\mathbf{F}}_{\alpha}^{(i)} \hat{\boldsymbol{\alpha}}_{i}+\hat{\mathbf{F}}_{0}^{(i)} \succeq 0, & i=1,2, \ldots, m \\
& \hat{\boldsymbol{\gamma}}_{j} \in \mathcal{Q}_{k_{j}}, & j=1,2, \ldots, q
\end{array}
$$

The matrices $\hat{\mathbf{C}}_{\sigma}, \hat{\mathbf{C}}_{\alpha}$, and $\hat{\mathbf{C}}_{\gamma}$ defines the equality constraints of the submodels, while $\hat{\mathbf{E}}_{\sigma}, \hat{\mathbf{E}}_{\alpha}$, and $\hat{\mathbf{E}}_{\gamma}$ defines the inequality constraints. The variables $\hat{\boldsymbol{\alpha}}$ and $\hat{\gamma}$ are discretised quantities similar to the stress field associated with the yield function, whereas $\hat{\gamma}$ is used to define the second-order constraints, and $\hat{\boldsymbol{\alpha}}$ is used to define the linear matrix inequalities together with the symmetric matrices $\hat{\mathbf{F}}_{\alpha}^{(i)}$ and $\hat{\mathbf{F}}_{0}^{(i)}$. The scalar $m$ is the number of linear matrix inequalities for the submodels while $q$ is the number of second-order constraints. The matrices will only be given implicitly in the following.

The submodel presented in Sec. 5 comprises both triaxial stress states as well as plane stress states, hence, both formulations of the Mohr-Coulomb criterion given in Sec. 2 will be utilised at the stress level of the submodel. The problem (12) comprises therefore both semidefinite constraints as well as second-order constraints.

\section{Macro finite element}

This section introduces a lower bound macro finite element for analysis and design of 3D structures. The general modelling concept of the element was illustrated in two dimensions in Fig. 2, where a precast concrete wall is modelled using plane stress elements and multiscale elements. On the element level, the proposed macro element is compatible with the plane stress element, and the stress states in the macro joint element are treated using a so-called submodel which incorporates corbel mechanisms to transfer shear.

The lower bound plane stress element has a linear stress field, hence, a safe stress field can be ensured by checking the yield function in the vertexes of the element. Moreover, to ensure a lower bound solution traction continuity has to be satisfied, and for the plane stress element the tractions are given in global coordinates, see Fig. 3. 


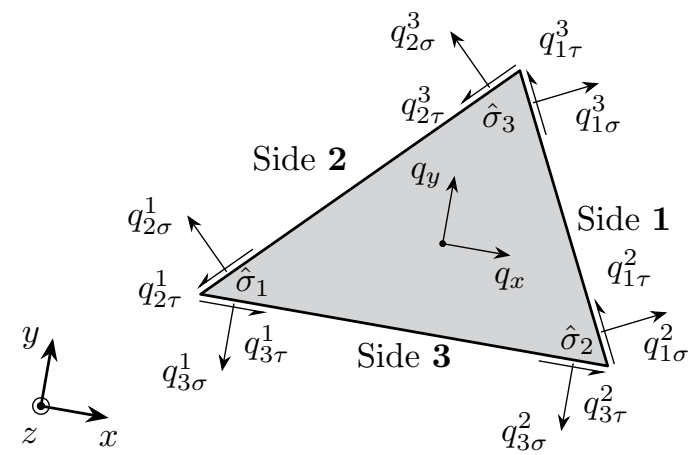

(a)

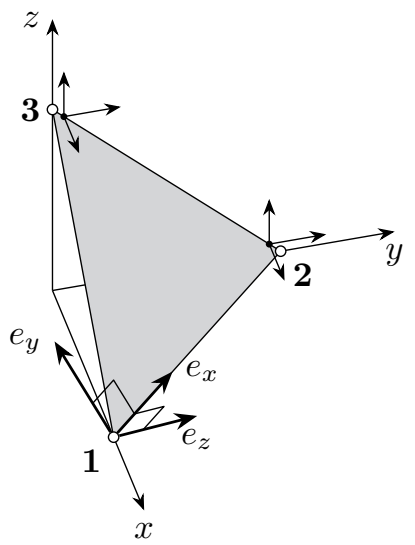

(b)

Figure 3: a) The element and tractions illustrated in the local coordinate system (adapted from [19]). b) The generalised plane stress element including local coordinate system and tractions in global coordinates for one of the element boundaries.

The joint is concerned with the transfer of shear forces, and the axial forces in the longitudinal direction are omitted in the present paper for simplicity. The joint element for two-dimensional shear joints [21] treated this as well, and a similar model can be added to the submodel criterion for the proposed joint element presented in the following section. Similarly, the necessary equilibrium equations to facilitate longitudinal forces can be added as well.

The submodel criterion to be presented in Sec. 5 assumes that the adjacent elements are oriented in right angles, which covers the vast majority of joints in practice, see e.g. the joints in Fig. 1. The formulation of the macro element, however, is general and applicable to any configuration of adjacent plane stress panels.

The joint element consists of a number of strips, one for each adjacent plane stress element, see Fig. 4. The strips are assumed to be in plane stress and balance the tractions of the adjacent plane stress triangles as well as internally within the joint. For the stress fields of the strips to be compatible with the plane stress elements, a linear variation is prescribed along the joint element.

Each strip has two stress components given in local coordinates, namely $\sigma_{y}$ and $\tau_{x y}$, hence, four stress variables are needed to describe the linear stress 
field. The element stress vector $\hat{\boldsymbol{\sigma}}_{e l}$ is given as:

$$
\hat{\boldsymbol{\sigma}}_{e l}=\left[\begin{array}{c}
\hat{\boldsymbol{\sigma}}_{1} \\
\vdots \\
\hat{\boldsymbol{\sigma}}_{N}
\end{array}\right]
$$

where $N$ is the number of strips and $\hat{\boldsymbol{\sigma}}_{i}$ denotes the stress vector of strip $i$ given as:

$$
\hat{\boldsymbol{\sigma}}_{i}=\left[\begin{array}{c}
\hat{\boldsymbol{\sigma}}_{i 1} \\
\hat{\boldsymbol{\sigma}}_{i 2}
\end{array}\right]=\left[\begin{array}{c}
\sigma_{y i 1} \\
\tau_{x y i 1} \\
\sigma_{y i 2} \\
\tau_{x y i 2}
\end{array}\right]
$$

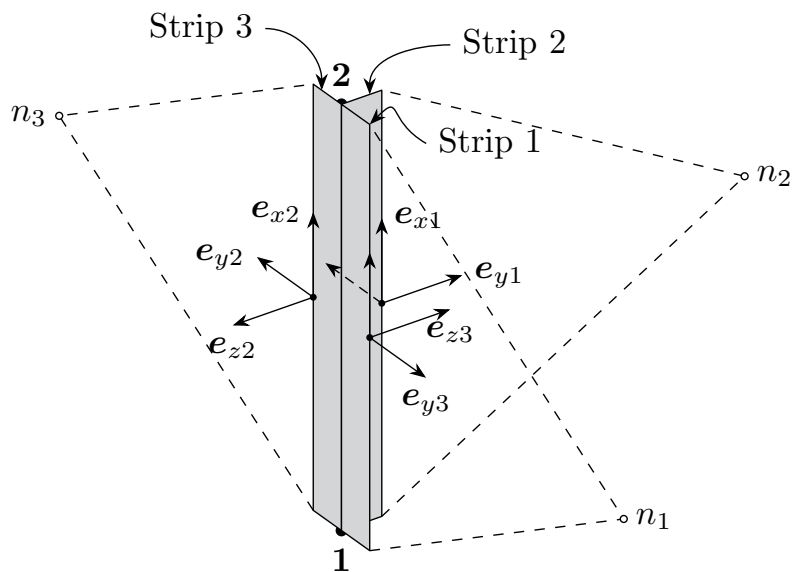

Figure 4: Sketch of a joint element with three adjacent plane stress elements: Local coordinate systems for the three joint strips are shown.

For consistent orientation, a local coordinate system for each strip is defined. The local $x$-axis is in the longitudinal direction of the joint element, while the $y$-axis is in the plane of the adjacent plane stress element. Given the vectors $\boldsymbol{v}_{12}$ going from node 1 to node 2 in Fig. 4 and $\boldsymbol{v}_{1 n_{i}}$ going from node 1 to $n_{i}$, where $n_{i}$ is the third node of the adjacent triangular element, the basis of the local coordinate system can be defined as:

$$
\boldsymbol{e}_{x i}=\frac{\boldsymbol{v}_{12}}{\left\|\boldsymbol{v}_{12}\right\|_{2}}, \quad \boldsymbol{e}_{z i}=\frac{\boldsymbol{v}_{12} \times \boldsymbol{v}_{1 n_{i}}}{\| \boldsymbol{v}_{12} \times \boldsymbol{v}_{1 n_{i} \|_{2}}}, \quad \boldsymbol{e}_{y i}=\boldsymbol{e}_{z i} \times \boldsymbol{e}_{x i}
$$


where $\|\boldsymbol{v}\|_{2}$ is the Euclidean norm of the vector $\boldsymbol{v}$. The transformation matrix for the $i$ th strip can be stated as $\mathbf{E}_{i}=\left[\begin{array}{lll}\boldsymbol{e}_{x i} & \boldsymbol{e}_{y i} & \boldsymbol{e}_{z i}\end{array}\right]$.

The contributions to traction continuity in global coordinates for strip $i$ at node $j$ can be stated as:

$$
\boldsymbol{q}_{i j}=\mathbf{E}_{i}\left[\begin{array}{cc}
0 & t_{i} l \\
t_{i} l & 0 \\
0 & 0
\end{array}\right]\left[\begin{array}{c}
\sigma_{y i j} \\
\tau_{x y i j}
\end{array}\right]=\tilde{\mathbf{P}}_{i}^{T} \hat{\boldsymbol{\sigma}}_{i j}
$$

where $\boldsymbol{q}_{i j}$ is the generalised nodal forces vector, $l$ is the length of the joint element, and $t_{i}$ is the thickness of strip $i$. (15) also defines $\tilde{\mathbf{P}}_{i}^{T}$ implicitly. Due to the linear stress field it is necessary to enforce traction continuity at the ends of the strip.

Internal traction equilibrium for the $N$ strips of the joint element is likewise enforced, which can be stated as:

$$
-\tilde{\mathbf{P}}_{1}^{T} \hat{\boldsymbol{\sigma}}_{1 j}-\cdots-\tilde{\mathbf{P}}_{N}^{T} \hat{\boldsymbol{\sigma}}_{N j}=0, \quad j=1,2
$$

where $j$ is the node number. Equilibrium on the element level for an joint element with $N$ adjacent plane stress elements can now be stated as follows:

$$
\boldsymbol{q}_{e l}=\left[\begin{array}{cccccc}
\tilde{\mathbf{P}}_{1}^{T} & & & & & \\
& \tilde{\mathbf{P}}_{1}^{T} & & & & \\
& & \ddots & & & \\
& & & \ddots & & \\
& & & & \tilde{\mathbf{P}}_{N}^{T} & \\
-\tilde{\mathbf{P}}_{1}^{T} & & & & & \tilde{\mathbf{P}}_{N}^{T} \\
& -\tilde{\mathbf{P}}_{1}^{T} & \ldots & \ldots & -\tilde{\mathbf{P}}_{N}^{T} & \\
& & & & -\tilde{\mathbf{P}}_{N}^{T}
\end{array}\right]\left[\begin{array}{c}
\hat{\boldsymbol{\sigma}}_{1} \\
\vdots \\
\hat{\boldsymbol{\sigma}}_{N}
\end{array}\right]=\hat{\mathbf{B}}_{e l}^{T} \hat{\boldsymbol{\sigma}}_{e l}
$$

where $\hat{\mathbf{B}}_{e l}^{T}$ is the element equilibrium matrix, and $\boldsymbol{q}_{e l}$ contains the contributions to the global equilibrium equations of the joint element. The number of stress variables and equations of the joint element depends on the number of adjacent plane stress elements, $N$, as seen in (17).

\section{Joint model}

We now consider a unit section of the joint in the shape of a rectangular box. This unit section is reinforced with U-bar loops from up to four 
boundaries which are placed in positions defined by $u, u_{y 1}$ and $u_{z 1}$ according to Fig. 5. The length of the unit section is $s$ and the widths are given as $t_{y}$ and $t_{z} . o_{y}$ and $o_{z}$ are the overlap of the U-bars. The distances between the U-bar pairs in the $y$ and $z$-directions, respectively, are assumed to be identical, i.e. $u=u_{y 1}+u_{y 2}=u_{z 1}+u_{z 2}$, which reduce the number of possible stress combinations inside the submodel greatly.

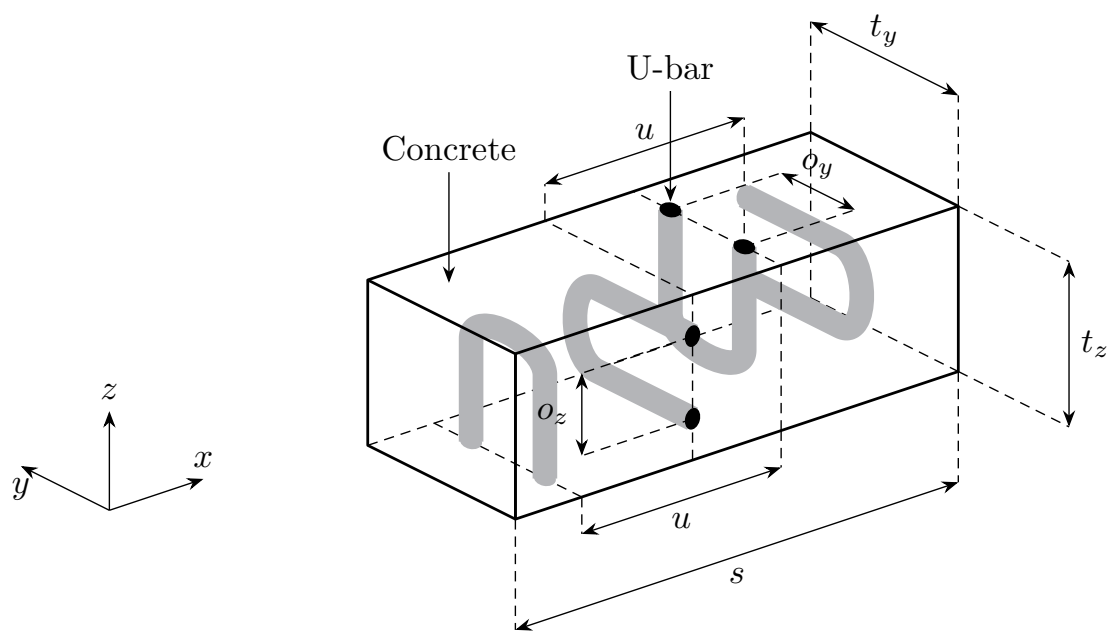

(a)

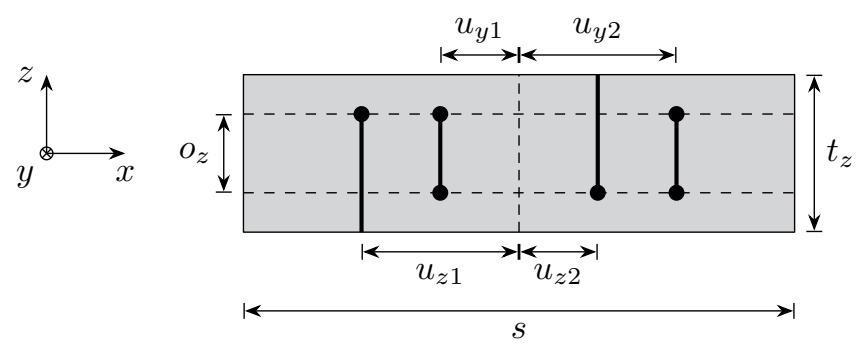

(b)

Figure 5: Submodel for the three-dimensional joint element: a) three-dimensional representation of the geometry including U-bar loops, b) two-dimensional sketch of the U-bar placement.

Joints are in practice always reinforced with a so-called locking bar in the longitudinal direction. In the present model, however, we assume that the considered unit section is adjacent to similar unit sections, hence the resulting forces are in equilibrium with these adjacent sections and the locking bar does 
not affect the behaviour of the unit section. Near the ends of a shear joint, no adjacent unit section is present, hence, a locking bar is needed to activate the corbels locally, but it is not considered in the present model. Likewise, contributions from dowel action or similar is neglected as the reinforcement generally only provide dissipation in the longitudinal direction.

Each of the four boundaries reinforced with U-bars can be subjected to a normal stress and a shear stress, $\sigma_{y}$ and $\tau_{x y}$, or $\sigma_{z}$ and $\tau_{z x}$, depending on the orientation. The stresses on the element level $\hat{\boldsymbol{\sigma}}_{e l}$ are given in the local coordinate systems of the particular strip, hence, a common coordinate system is needed, and all stresses are transformed to the coordinate system of strip 1:

$$
\tilde{\mathbf{S}}_{i j}=\mathbf{E}_{1}^{T} \mathbf{E}_{i} \mathbf{S}_{i j} \mathbf{E}_{i}^{T} \mathbf{E}_{1}
$$

where $\mathbf{E}_{i}$ is the transformation matrix of strip $i$, and $\mathbf{S}_{i j}$ is the stress tensor of strip $i$ at node $j$, e.g. for strip 1 at node 2 - which is always chosen for the common coordinate system - we have

$$
\mathbf{S}_{12}=\left[\begin{array}{ccc}
0 & \tau_{x y 12} & 0 \\
\tau_{x y 12} & \sigma_{y 12} & 0 \\
0 & 0 & 0
\end{array}\right]
$$

Most of the components in $\mathbf{S}_{i j}$ are equal to zero as the strips only have two stress components, which simplifies the calculations. The shear stress component of $\tilde{\mathbf{S}}$ is used for the corbels presented in the following section. The equilibrium equations of the element ensures that the normal stress components of $\tilde{\mathbf{S}}_{i j}$ are balanced, and the normal stresses are simply added to the final stress field of the submodel, which must satisfy the Mohr-Coulomb criterion.

\subsection{Local shear transfer via corbels}

A mechanical model for the transfer of shear from one plane to another, e.g. from $\tau_{x y}$ to $\tau_{z x}$, is needed. For this purpose a concrete corbel is considered. The corbel utilises the transverse reinforcement of the joint, i.e. the U-bar loops, to transform the shear stress (from $\hat{\mathbf{S}}$ ) acting on the boundary of the joint to a normal stress in the core of the joint. This is illustrated in Fig. 6(a).

Fig. 6(b) shows a corbel subjected to a shear stress $\tau_{z x}$ from the transformed stress state of the particular strip of the macro element. The loop 


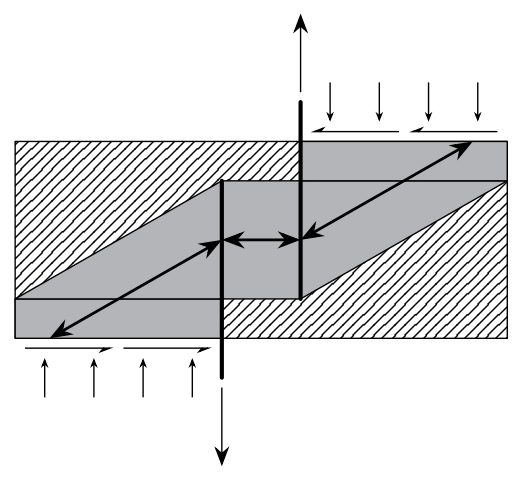

(a)

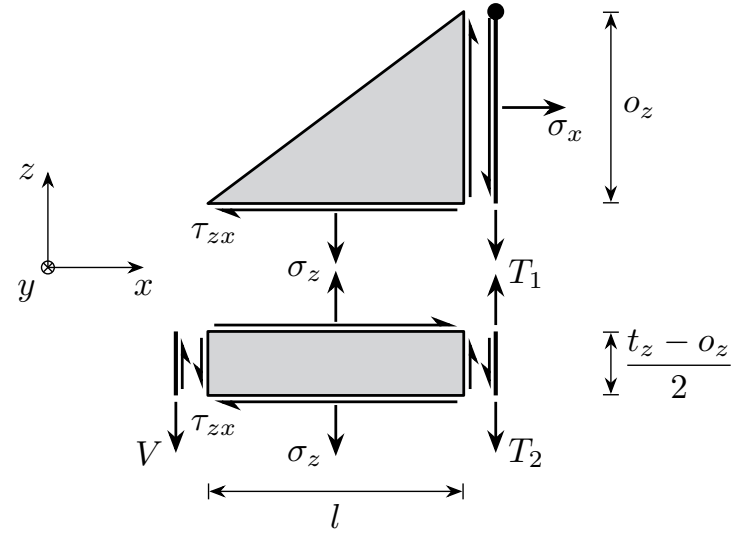

(b)

Figure 6: a) Sketch of two corbel mechanisms working in two-dimensions. b) Twodimensional representation of a corbel in the $x z$-plane transforming a shear stress $\tau_{z x}$ to a normal stress $\sigma_{x}$. Positive directions of forces and stresses are shown. The panels indicated by gray has a out-of-plane thickness of $o_{y}$.

reinforcement is activated and the stringer force $T$ in the reinforcement balances the stress $\sigma_{z}$ and the stringer force $V$. The rectangular panel will have constant shear stress, while the triangle will be in uniaxial compression. For a single corbel, see Fig. 6(b), we have the following variables:

$$
\alpha_{i}=\left[\begin{array}{llllll}
\sigma_{x}^{(i)}, & \sigma_{z}^{(i)}, & \tau_{z x}^{(i)}, & T_{1}^{(i)}, & T_{2}^{(i)}, & V^{(i)}
\end{array}\right]^{T}
$$

or

$$
\alpha_{i}=\left[\begin{array}{llllll}
\sigma_{x}^{(i)}, & \sigma_{y}^{(i)}, & \tau_{x y}^{(i)}, & T_{1}^{(i)}, & T_{2}^{(i)}, & V^{(i)}
\end{array}\right]^{T}
$$

depending on the orientation of the corbel. The following system of equilibrium equations can be derived for a single corbel:

$$
\left[\begin{array}{cccccc}
o_{z} o_{y} & 0 & -l o_{y} & 0 & 0 & 0 \\
0 & -l o_{y} & 0 & 0 & -1 & -1 \\
0 & -l o_{y} & o_{z} o_{y} & 0 & 0 & 0 \\
0 & 0 & -\frac{t_{z}-o_{z}}{2} o_{y} & 0 & 0 & -1 \\
0 & 0 & -\frac{t_{z}-o_{z}}{2} o_{y} & 1 & -1 & 0 \\
0 & 0 & -o_{z} o_{y} & -1 & 0 & 0
\end{array}\right]\left[\begin{array}{c}
\sigma_{x} \\
\sigma_{z} \\
\tau_{z x} \\
T_{1} \\
T_{2} \\
V
\end{array}\right]=\mathbf{0}
$$


The first three equations in (21) ensure vertical, horizontal, and moment equilibrium, while the last three ensure equilibrium for the stringers. The stresses $\sigma_{x}$ and $\sigma_{z}$ will practically always be negative, i.e. compressive, and the same goes for the stringer force $V$. No reinforcement is located at the position of the leftmost stringer, hence, the stringer is a so-called compression stringer which cannot take any tension.

A single corbel transforms a shear stress into a normal stress in the core of the joint. Several corbels are therefore needed to transfer shear from one plane to another. Moreover, the corbels are given a predefined length $l$, see Fig. 6, however, the optimal value of $l$ depends on the reinforcement and loading. Four corbels for each of the four boundaries of the joint is therefore used, thus, the complete submodel features up to 16 corbels, four for each U-bar loop in the considered joint section.
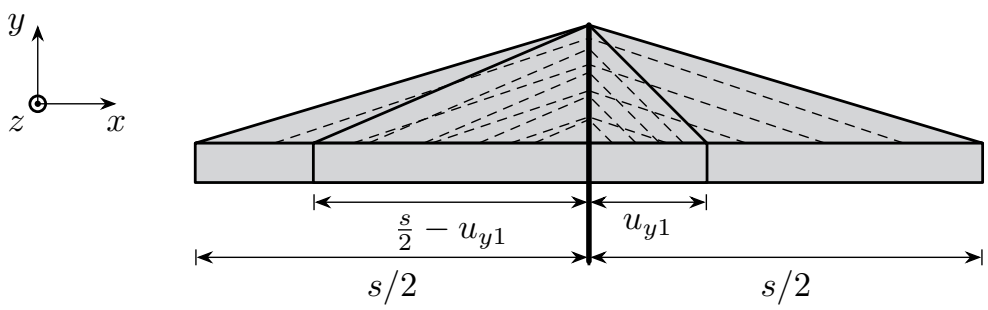

Figure 7: Four corbel models around a single U-bar: The length is fixed at $s / 2$ for the two largest, while the length of the two smallest depends on the position of the U-bar in the unit joint section. Dashed lines indicate the load path through the triangular corbels. Some of the corbels overlap and their stress fields are added to obtain the actual stress state.

Fig. 7 shows the four corbels around a U-bar. As shown in Fig. 7, some of the corbels overlap, and it is therefore necessary to add the stress fields together to obtain the actual stress field of the submodel. Each of the corbels can transfer a shear stress to a normal stress in the centre of the joint, which then can be transferred to a shear stress in a different plane via another corbel. This is illustrated schematically in Fig. 8 for two corbels.

Combining the up to 16 corbels requires four equations - one for each U-bar loop - which enforce equilibrium for the normal stresses $\sigma_{x}$ according to the positions of the corbels together with four transfer boxes, see Fig. 8.

Fig. 9 shows the transfer of normal stresses $\sigma_{x}$ schematically, where each set of arrows is located at the position of an U-bar loop. The four equilibrium 


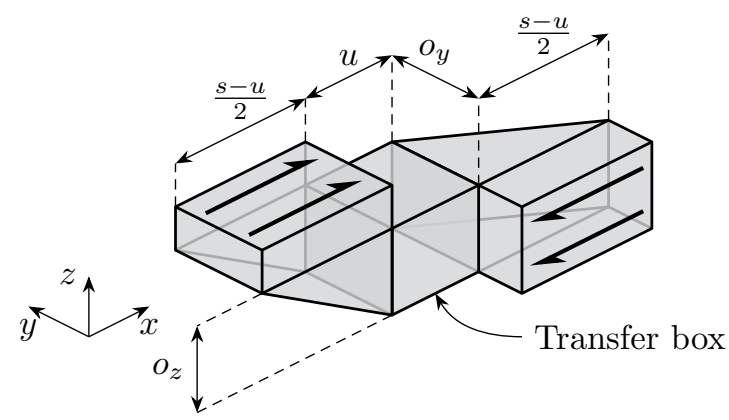

Figure 8: Shear transfer from one plane to another via two corbels. The central transfer box will experience uniaxial compression in the $x$-direction. Equilibrium of the corbels is ensured by stringer forces and confinement not shown here.

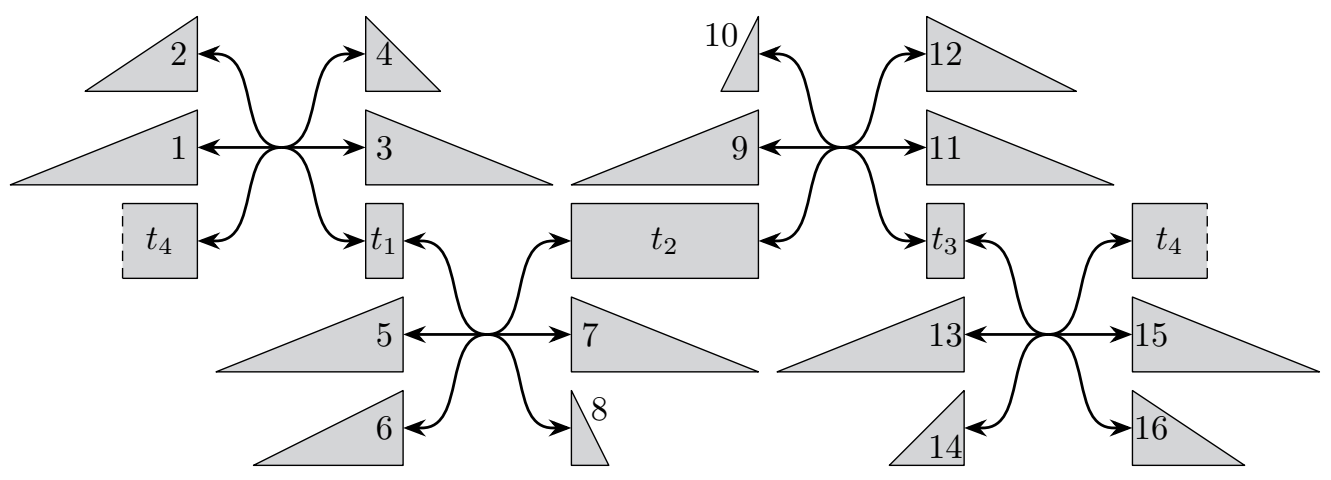

Figure 9: Interaction of the 16 corbels and four transfer boxes illustrated schematically: The triangles represent a corbel mechanism, while the rectangles represent the transfer boxes. Each set of arrows represent an equilibrium equation. The size and locations of corbels are not to scale.

equations are given as

$$
\begin{aligned}
& \sigma_{x}^{(1)}+\sigma_{x}^{(2)}-\sigma_{x}^{(3)}-\sigma_{x}^{(4)}+\sigma_{x}^{t 4}-\sigma_{x}^{t 1}=0, \\
& \sigma_{x}^{(5)}+\sigma_{x}^{(6)}-\sigma_{x}^{(7)}-\sigma_{x}^{(8)}+\sigma_{x}^{t 1}-\sigma_{x}^{t 2}=0, \\
& \sigma_{x}^{(9)}+\sigma_{x}^{(10)}-\sigma_{x}^{(11)}-\sigma_{x}^{(12)}+\sigma_{x}^{t 2}-\sigma_{x}^{t 3}=0, \\
& \sigma_{x}^{(13)}+\sigma_{x}^{(14)}-\sigma_{x}^{(15)}-\sigma_{x}^{(16)}+\sigma_{x}^{t 3}-\sigma_{x}^{t 4}=0,
\end{aligned}
$$

where $\sigma_{x}^{(i)}$ is the stress in the $x$-direction associated with the $i$ th corbel, see Fig. 6. The first four corbels are associated with the first U-bar loop, the next four with the second U-bar loop and so on, see Fig. 9 for the numbering. $\sigma_{x}^{t j}$ is the normal stress of the $j$ th transfer box. Two corbels associated with 
the same U-bar, e.g. the two corbels on the left-hand side in Fig. 7, can work together, each transferring a fraction of the total shear force.

The stress states of the 16 corbels are combined to obtain the actual stress field within the unit joint section. The corbels overlap to some degree, see Fig. 7 where some of the corbels in the same plane overlap, and it is therefore necessary to superimpose the appropriate stress states. Depending on the values of $u, u_{y 1}$, and $u_{z 1}$ up to ten triaxial stress states are present inside the unit section. Each of these stress states are given by three normal stresses and two shear stresses.

$\tau_{y z}$ is zero for all strips in their local coordinate system. The transformation from the local coordinate system of any strip to the coordinate system of strip 1 is equivalent to rotating the coordinate system about the local $x$-axis, hence, $\tau_{y z}$ will remain zero. The triaxial stress states in the joint concrete must satisfy the Mohr-Coulomb criterion presented in Sec. 2. Moreover, the rectangular panels in the corbels will experience plane stress, which must satisfy the Mohr-Coulomb criterion for plane stress also presented in Sec. 2.

The U-bar loops are subject to tension in order to activate the corbel mechanisms, and the tensile stress must be below the tensile strength:

$$
0 \leq T_{i} \leq f_{y} A_{s u}
$$

where $f_{y}$ is the yield strength and $A_{s u}$ is the cross sectional area. It is assumed that the reinforcement only carries tension as seen in (23). The compression stringers illustrated in Fig. 6 must be in compression, i.e. $V$ must be non-positive:

$$
V \leq 0
$$

The submodel requires second-order constraints as well as semidefinite constraints since the concrete experience both plane stress and triaxial stress. The macro joint element and submodel are implemented in Matlab and the commercial optimisation solver MOSEK [31].

\section{Analysis and discussion}

\subsection{Corner joint subject to shear}

First, a corner joint subjected to shear is analysed using a single joint element with the submodel criterion, and the results are compared to the current design criterion of the Eurocode 2. Comparison to experimental 


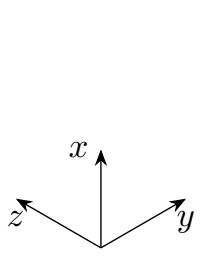

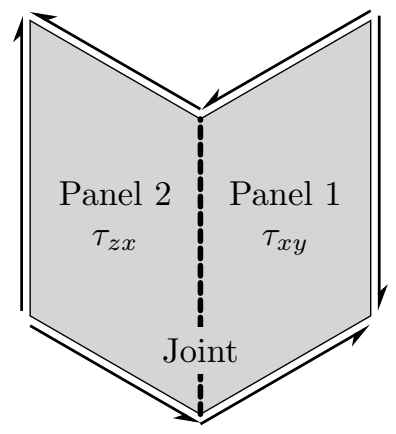

(a)

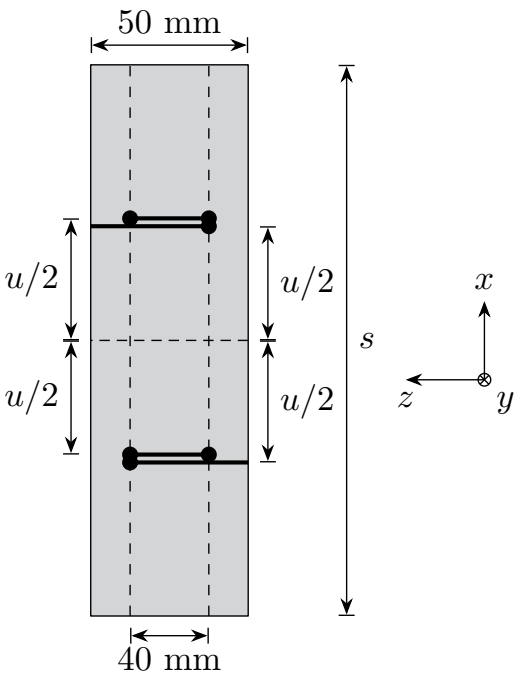

(b)

Figure 10: a) Corner joint connecting two reinforced concrete panels subject to pure shear analysed using a single joint element. b) Dimensions of the considered joint: $s$ takes the values of $100 \mathrm{~mm}, 200 \mathrm{~mm}$, or $400 \mathrm{~mm}$, while $u$ is varied.

results would be preferable, however, as mentioned experimental results for corner joints have not been published to the best knowledge of the authors.

Fig. 10 shows the corner joint connecting two precast concrete panels as well as the loading, which is applied such that the joint is loaded in pure shear. For the Eurocode 2, the shear capacity of a keyed joint can be calculated as:

$$
\tau=c f_{t} \frac{A_{k e y}}{A_{c}}+\mu \rho f_{y} \leq \frac{1}{2} \nu f_{c} \frac{A_{k e y}}{A_{c}}
$$

where $c=0.5$ is a parameter which relates the tensile strength $f_{t}$ to the cohesion, and $\mu=0.9$ is the friction coefficient used for keyed joints. $A_{k e y}$ is the area of the keys and $A_{c}$ is the total area of the joint. $\rho$ is defined as

$$
\rho=\frac{\sum A_{s u}}{A_{c}}
$$

$\nu$ is the so-called effectiveness factor, which accounts for microcracking and softening when using a rigid-plastic material model for concrete. An effectiveness factor of $\nu=0.7-f_{c} / 200\left(f_{c}\right.$ in $\left.\mathrm{MPa}\right)$ is used for the comparison. 
The joint is analysed for varying value of $u$, see Fig. 5 , with $u / 2=u_{z 1}=$ $u_{y 1}$. The following parameters are used:

$$
f_{t}=0 \mathrm{MPa}, t_{z}=t_{y}=50 \mathrm{~mm}, o_{z}=o_{y}=40 \mathrm{~mm}
$$

Moreover, the angle of internal friction is taken as $37^{\circ}$, i.e. $k=4$, which is commonly used for reinforced concrete. In practice, mortar with low aggregate size is often used, which may reduce the angle of friction. For the Eurocode 2 design formula $(24), f_{t}=0.21 f_{c}^{2 / 3}$ and $A_{k e y} / A_{c}=0.5$ are used. Three different types U-bar loops commonly used in practice are analysed using different values of U-bar spacing, $s$.

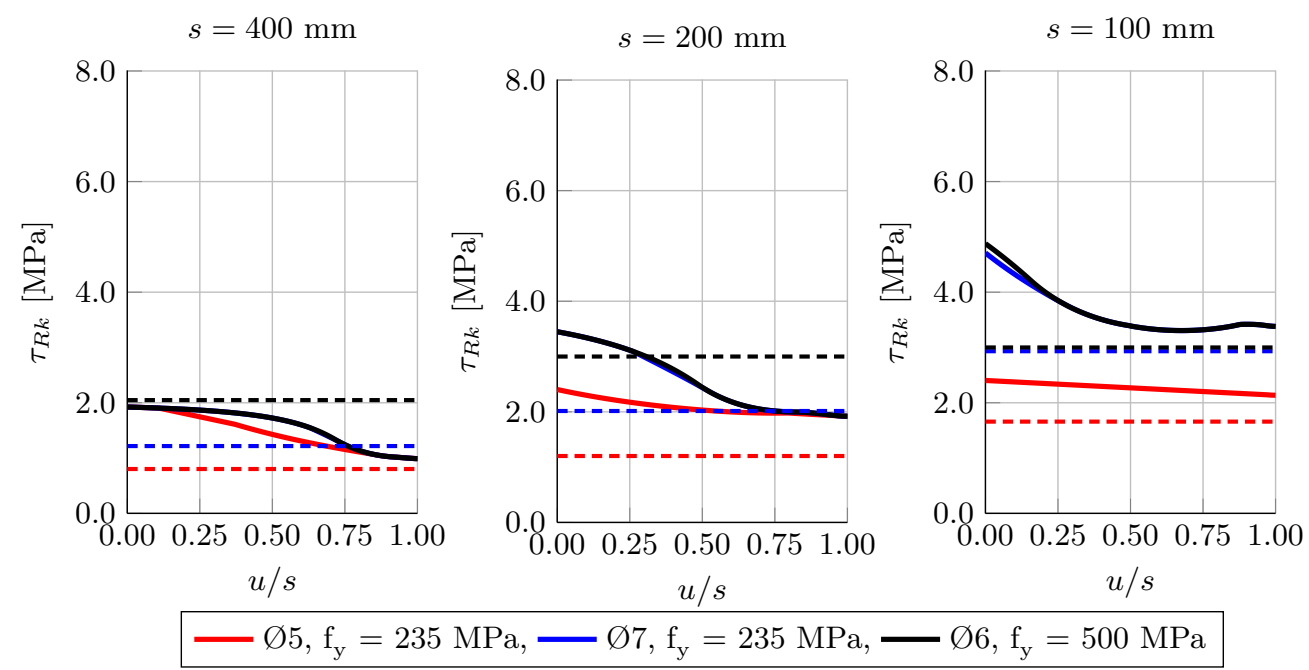

Figure 11: Characteristic shear capacity of the corner joint with $f_{c}=20 \mathrm{MPa}$ and different values of $s$ : The results of the joint element is represented using solid lines, while the capacity predicted using the Eurocode 2 is shown with dashed lines.

Fig. 11 and 12 show the shear capacity of the corner joints for the three types U-bar loops. It is observed that the values of $u$ and $s$ affect the capacity of the joint element and submodel to some degree. Moreover, the concrete strength heavily affects the capacity for the joints with $\varnothing 7$ and $\varnothing 6$ U-bars (blue and black lines).

The shear capacity estimated with the Eurocode 2 design equation is somewhat similar to the shear capacity of the joint element, however, for low values of $s$ the Eurocode underestimate the capacity, while it overestimates the capacity for larger values of $s$ depending on $u$ compared to the joint 


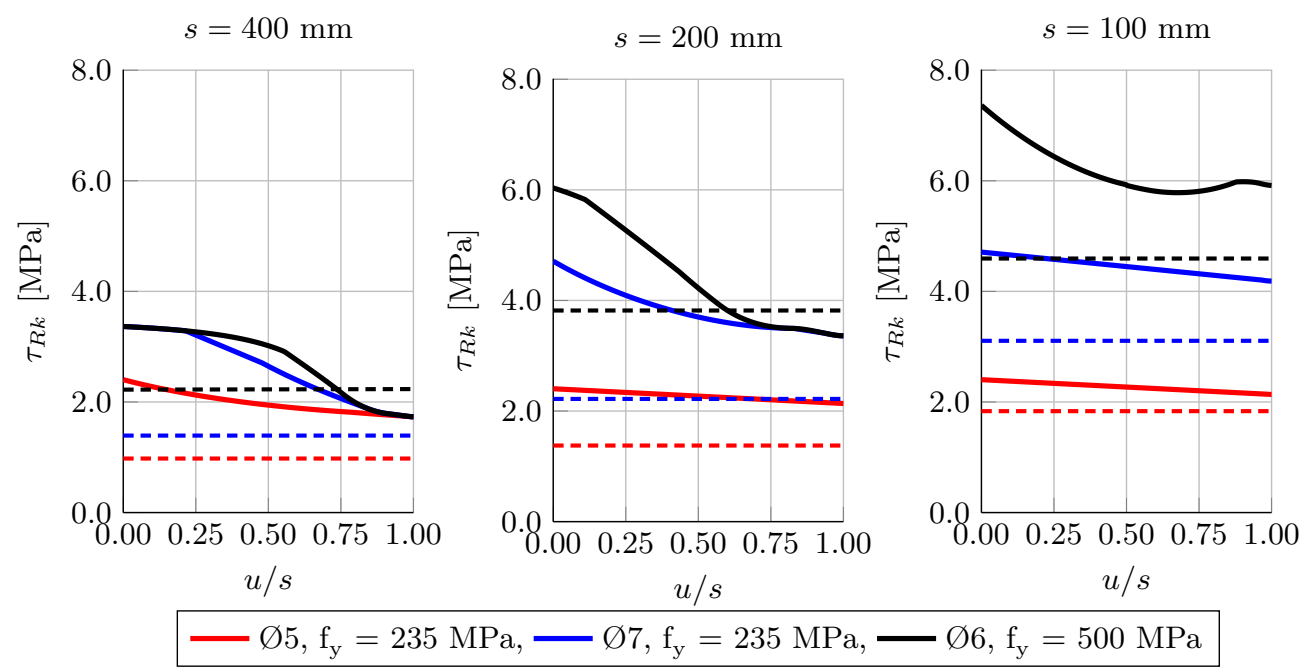

Figure 12: Characteristic shear capacity of the corner joint with $f_{c}=35 \mathrm{MPa}$ and different values of $s$ : The results of the joint element is represented using solid lines, while the capacity predicted using the Eurocode 2 is shown with dashed lines.

element. Based on the analysis it can be concluded that it is necessary to consider the stress field inside the joint for design.

\subsection{Four-storey stairwell with door openings}

Herfelt et al. [22] analysed a four-storey stairwell with door openings subjected to shear and torsion using the generalised plane stress element. The stairwell is now considered as a precast concrete structure, and the corners are modelled using the presented joint element.

The stairwell including the positions of the joints are seen in Fig. 13. The dimensions of the wall as well as meshes for the model are also given in the figure. The door openings have a height of 2.10 metres and a width of 0.90 metres. The precast concrete panels have a thickness of $180 \mathrm{~mm}$ and are reinforced with two layers of $\varnothing 8$ rebars per $150 \mathrm{~mm}$ in both directions. The reinforcement has a design yield strength of $f_{y d}=458 \mathrm{MPa}$, and the concrete has a design compressive strength of $f_{c d}=21.4 \mathrm{MPa}$, while the tensile strength is taken as zero. Considering a single U-bar loop, the reinforcement ratio is given as

$$
\Phi=\frac{A_{s u} f_{y}}{s t f_{c}}
$$




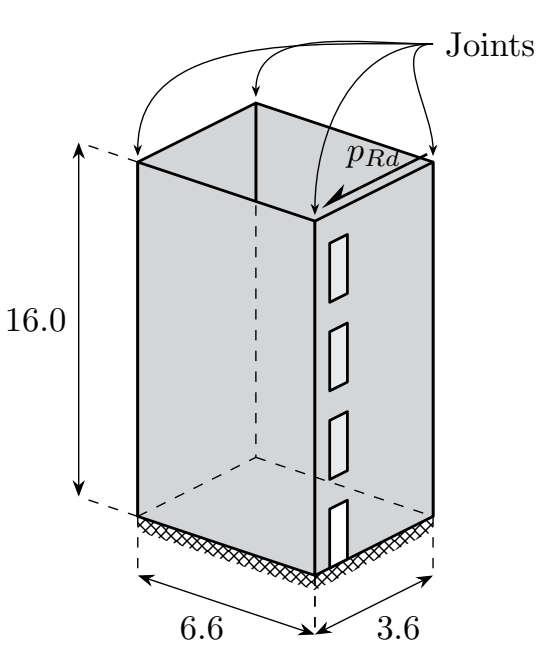

(a)

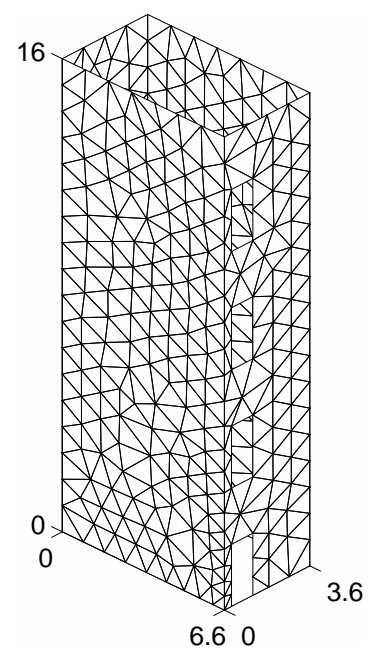

(b)

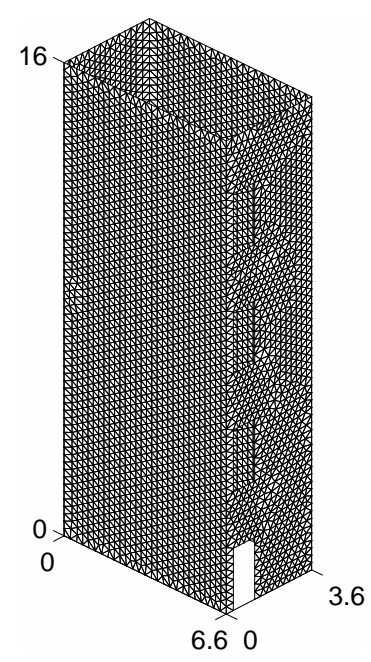

(c)

Figure 13: Four-storey stairwell subjected to bending and torsion: a) Sketch showing loading and joints located in the vertical corners are modelled using the joint element[22], b) coarse mesh with 864 triangular elements, c) fine mesh with 11,379. All dimensions are given in metres.

For the joints, a thickness of $t_{z}=t_{y}=180 \mathrm{~mm}$ is used with an overlap of $o_{z}=o_{y}=50 \mathrm{~mm}$ and $s=300 \mathrm{~mm}$, see Fig. 10(b). $f_{c d}=21.4 \mathrm{MPa}, f_{t}=0$, and $k=4$ are used for the joint concrete as well. The reinforcement ratio of the joint is varied and the results are illustrated in Fig. 14 for two meshes generated using GiD v12 [32]; a coarse mesh with 864 plane stress elements, and a fine mesh with 11,379 plane stress element, see Fig. 13(b) and (c). Moreover, the stairwell is analysed for two values of $u$ to assess the effect of the reinforcement layout.

Fig. 14 shows that the capacity depends on the joint reinforcement to some degree, however, the joints will hardly affect the capacity provided sufficient reinforcement, i.e. $\Phi \geq 0.004$ corresponding to $\varnothing 5$ U-bar loops per $544 \mathrm{~mm}$ assuming a design strength of $214 \mathrm{MPa}$ which is far below what is typically used in practice. It is seen that the model with the joint elements approach the capacity of the model without the joint from below, which is to be expected from a lower bound element. It is also seen that the fine mesh predicts a larger capacity.

From Fig. 15 it can be seen that the joints push the structure towards a more evenly distribution of the shear stresses across the corner. For 


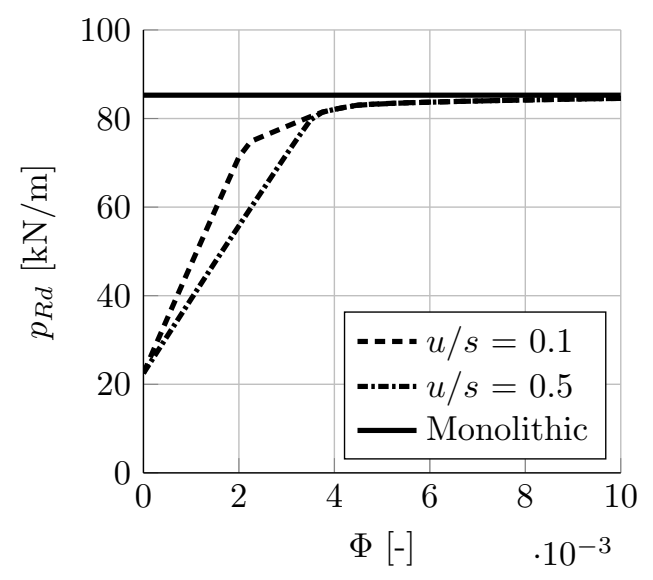

(a) Coarse mesh

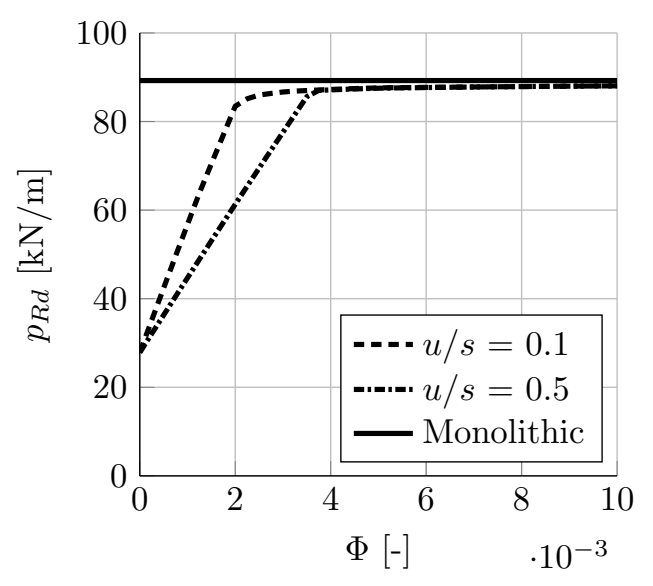

(b) Fine mesh

Figure 14: Design capacity of the stairwell as a function of the reinforcement ratio of the joints for two different values of $u$.

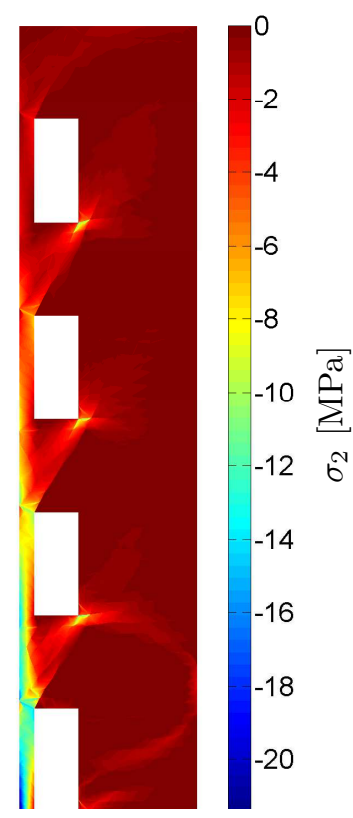

(a) Joints: $\Phi=0.001$, $p_{R d}=47.12 \mathrm{kN} / \mathrm{m}$

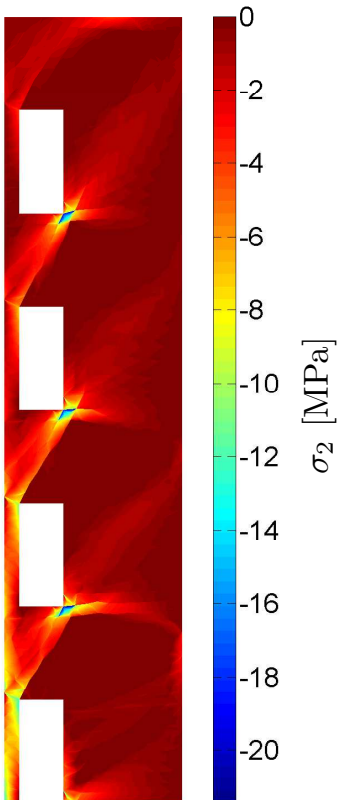

(b) Joints: $\Phi=0.004$, $p_{R d}=87.14 \mathrm{kN} / \mathrm{m}$

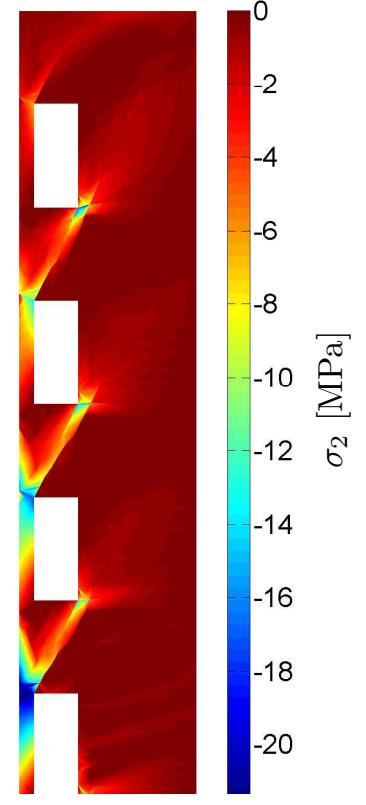

(c) Monolithic: $p_{R d}=89.25 \mathrm{kN} / \mathrm{m}$

Figure 15: Comparison of the smallest principal stress for the wall with the door openings using the fine mesh with and without joints $(u / s=0.5)$. 
$\Phi=0.001$ shown in Fig. 15(a), large compressive stresses are observed near the bottom door opening. This is due to the fact that the joints do not have sufficient shear capacity and the stresses have to be transferred to the foundations via the wall itself. Fig. 15(c) shows large compressive stresses above $20 \mathrm{MPa}$ near the bottom door opening which is possible since no criterion is enforced on the stresses in the corner of the structure.

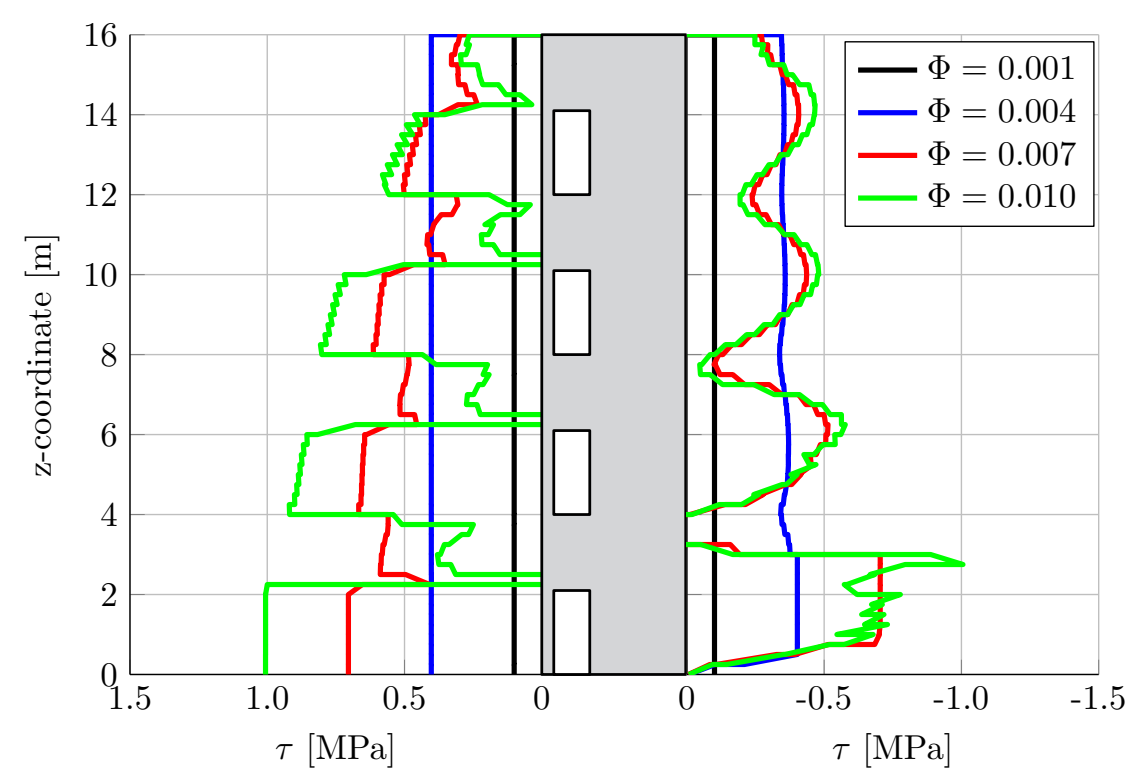

Figure 16: Shear stress distribution over the height of the structure in the joints near adjacent to the slender wall with the door openings. The shear stress is shown for four different reinforcement degrees $\Phi$ using the fine mesh and $u / s=0.5$ for the joints. The wall structure is shown in the centre.

Fig. 16 shows that for $\Phi=0.001$ and 0.004 , the shear stress in the joints near the door openings will be constant over the entire height. In order to activate the joints over the entire height, significant ductility is needed. Increasing the reinforcement degree means that only a small portion of the joints are utilised fully, hence, the requirement to the ductility is lower, and the structure is more robust. The effect of the door openings on the shear stress is clearly shown in Fig. 16 for $\Phi=0.007$ and 0.010 . The forces are primarily transferred as diagonal compression in the panels, hence, this jagged pattern of shear stresses is generated. The effect of the door openings is also seen to some degree for the joint to the right of the wall, where an almost wave-like distribution is observed for $\Phi=0.007$ and 0.010 . 
The analysis has shown that the proposed multiscale joint element makes modelling of real size structures possible. Moreover, the stairwell model using the fine mesh only required a CPU time of approximately 65 seconds on a desktop PC with an Intel Xeon CPU W3565 with 8 CPUs and $3.2 \mathrm{GHz}$ clock frequency. The low computational time is a major advantage over general non-linear finite element models.

\section{Conclusion}

In practice, design and analysis of precast concrete structure in the ultimate limit state is primarily done using simple manual methods and linear finite element analysis. The manual methods are often based on limit analysis and provide efficient tools for assessment of the capacity. For complex structures, however, it becomes difficult to obtain a decent solution - especially for structures in three dimensions. Moreover, it is rather difficult to account for the behaviour of the in-situ cast joints.

A lower bound multiscale joint element was presented. The element was designed for interaction with a generalised plane stress element with the scope of modelling of real life precast concrete structures. A mechanical submodel was proposed as the yield function of the macro joint element. The submodel used corbels to transfer shear stresses from one plane to another and the resulting triaxial stress field within the joint was checked against the Mohr-Coulomb criterion.

Unfortunately, no experiments of joints in three dimensions have been published, thus, the joint element and submodel was analysed by comparison to the Eurocode criterion. The results of the joint element and the Eurocode design equation were somewhat close and for heavily reinforced joints, the joint element predicted a larger capacity.

A four-storey precast concrete stairwell with door openings was analysed. The precast panels were connected by in-situ cast joints in the corners, and it was observed that the capacity of the joints are crucial to the overall behaviour of the wall. The reinforcement of the joints heavily affects the capacity, especially at low degrees of reinforcement. The joints also affected the stress field considerably, and the shear stresses were distributed more evenly across the corner joint. Higher levels of reinforcement increase the robustness of the structure considerably and lower the requirement to the ductility of the joints and panels. 
The proposed multiscale joint model has shown significant potential, however, validation by comparison to experimental results is necessary. It can be concluded that the presented framework and model will enable optimisation of precast concrete structures, and the lower bound property of the model is highly desirable for practical design.

\section{Acknowledgement}

The authors would like to thank the ALECTIA Foundation and Innovation Fund Denmark for financial support of the research presented in this paper.

\section{References}

\section{References}

[1] J. Fauchart, P. Cortini, Étude expérimentale de joints horizontaux entre panneaux préfabriqués pour murs de batiments, Annales de LInstitut Technique du Batiment et dês Travaux Publics 300 (1972) 86-103.

[2] F. Bljuger, Determination of deformability characteristics of vertical shear joints in precast buildings, Building and Environment 11 (1976) $277-282$.

[3] K. Hansen, S. O. Olesen, SBI-Report 97: Keyed Shear Joints, Statens Byggeforskningsinstitut, 1976.

[4] European Committee for Standardization, En 1992-1-1 eurocode 2: Design of concrete structures - part 1-1: General rules and rules for buildings (2005).

[5] M. A. Herfelt, P. N. Poulsen, L. C. Hoang, J. F. Jensen, Numerical limit analysis of keyed shear joints in concrete structures, Structural Concrete 17 (3) (2016) 481-490.

[6] A. A. Gvozdev, The determination of the value of the collapse load for statically indeterminate systems undergoing plastic deformation, International Journal of Mechanical Sciences 1 (4) (1960) 322-335. 
[7] W. Prager, The general theory of limit design, in: Proceedings of the 8th International Congress on theoretical and Applied Mechanics, Istanbul, Vol. 19, 1952, pp. 65-72.

[8] D. Drucker, W. Prager, H. Greenberg, Extended limit design theorems for continuous media, Quarterly of Applied Mathematics 9 (1952) 381389 .

[9] K. W. Johansen, Yield-line theory, Cement and Concrete Association, 1962.

[10] B. C. Jensen, On the ultimate load of vertical, keyed shear joints in large panel buildings, in: Symposium on Bearing Walls in Warsaw, Vol. 8, 1975 , p. 13th.

[11] J. Christoffersen, Ultimate capacity of joints in precast large panel concrete buildings, Ph.D. thesis, Technical University of Denmark (1997).

[12] M. P. Nielsen, L. C. Hoang, Limit Analysis and Concrete Plasticity, Third Edition, Taylor \& Francis, 2010.

[13] fib bulletin 43, Structural connections for precast concrete buildings (2008).

[14] T. Belytschko, P. Hodge, Plane stress limit analysis by finite elements, Journal of the Engineering Mechanics Division 96 (6) (1970) 931-944.

[15] E. Anderheggen, H. Knöpfel, Finite element limit analysis using linear programming, International Journal of Solids and Structures 8 (1972) $1413-1431$.

[16] E. Christiansen, On the collapse solution in limit analysis, Archive for Rational Mechanics and Analysis 91 (2) (1986) 119-135.

[17] S. W. Sloan, Lower bound limit analysis using finite elements and linear programming, International Journal for Numerical and Analytical Methods in Geomechanics 12 (1988) 61-77.

[18] S. Krenk, L. Damkilde, O. Høyer, Limit analysis and optimal design of plates with equilibrium elements, Journal of Engineering Mechanics 120 (1994) 1237-1254. 
[19] P. N. Poulsen, L. Damkilde, Limit state analysis of reinforced concrete plates subjected to in-plane forces, International Journal of Solids and Structures 37 (2000) 6011-6029.

[20] A. Makrodimopoulos, C. Martin, Lower bound limit analysis of cohesivefrictional materials using second-order cone programming, International Journal for Numerical Methods in Engineering 66 (4) (2006) 604-634.

[21] M. A. Herfelt, P. N. Poulsen, L. C. Hoang, J. F. Jensen, Lower bound equilibrium element and submodel for shear joints in precast concrete structures, Engineering Structures 135 (2017) 1 - 9 .

[22] M. A. Herfelt, P. N. Poulsen, L. C. Hoang, J. F. Jensen, Lower bound plane stress element for modelling $3 \mathrm{~d}$ structures, Proceedings of the Institution of Civil Engineers-Engineering and Computational Mechanics (2017) 1-11.

[23] Y. Nesterov, A. Nemirovsky, A general approach to polynomial-time algorithms design for convex programming, report, Central Economical and Mathematical Institute, USSR Academy of Sciences, Moscow (1988).

[24] E. D. Andersen, C. Roos, T. Terlaky, On implementing a primal-dual interior-point method for conic quadratic optimization, Mathematical Programming 95 (2) (2003) 249-277.

[25] M. S. Lobo, L. Vandenberghe, S. Boyd, H. Lebret, Applications of second-order cone programming, Linear algebra and its applications 284 (1) (1998) 193-228.

[26] C. Bisbos, P. Pardalos, Second-order cone and semidefinite representations of material failure criteria, Journal of Optimization Theory and Applications 134 (2) (2007) 275-301.

[27] K. Krabbenhøft, A. Lyamin, S. Sloan, Formulation and solution of some plasticity problems as conic programs, International Journal of Solids and Structures 44 (5) (2007) 1533-1549.

[28] L. Vandenberghe, S. Boyd, Semidefinite programming, SIAM review 38 (1) (1996) 49-95. 
[29] K. Krabbenhøft, A. Lyamin, S. Sloan, Three-dimensional mohr-coulomb limit analysis using semidefinite programming, Communications in $\mathrm{Nu}-$ merical Methods in Engineering 24 (11) (2008) 1107-1119.

[30] K. P. Larsen, Numerical limit analysis of reinforced concrete structures, Ph.D. thesis, Technical University of Denmark (2010).

[31] MOSEK ApS, The MOSEK optimization toolbox for MATLAB manual. Version 7.1 (Revision 33) (2015).

URL https://www.mosek.com/

[32] R. Ribó, M. Pasenau, E. Escolano, J. Ronda, L. González, Gid reference manual, CIMNE, Barcelona. 